\title{
Closing the gap between disaster mental health research and practice: evidence for socio-ecological mental health interventions through multilevel research
}

\author{
Tim R. Wind \& Ivan H. Komproe ${ }^{1}$
}

PhD, Clinical Psychologist at Centrum '45 (the Netherlands) In this research, he collaborates with HealthNet TPO and Harvard School of Public Health, ${ }^{1} \mathrm{PhD}$, is Psychologist and Professor at the Faculty of Social and Behavioral Sciences of Collective Trauma, Utrecht University, the Netherlands and Director Research and Development at HealthNet TPO, the Netherlands

\section{Abstract}

Socio-ecological interventions assume that there are 'links' between the individual process that determines disaster mental health and the social context one lives in. However, there is insufficient empirical basis for this claim. This paper summarises the main findings from a research programme, in which two advanced statistical techniques on data from two floods were applied, respectively Uttar Pradesh, India 2008 and Morpeth, England, 2008. By means of multilevel structural equation modelling it was found that individual psychosocial resources (coping behaviour and social support) are employed more parsimoniously and effectively when disaster affected individuals can rely on a trustworthy and effective social community. Additionally, using multilevel confirmatory factor analyses to address screening outcomes yielded two methodological problems: nested variance due to the disaster context and poor construct validity. These can be illustrated, but not dismissed without applying advanced statistical analyses. The findings strongly suggest that community interventions promoting social context and individual interventions not only share the same objective, but also impact mental health via the same individual mechanisms.

Keywords: England, India, mental health, multilevel interventions, social capital

\section{KEY IMPLICATIONS FOR PRACTICE}

- Socio-ecological interventions promoting social context and individual interventions exert effect on mental health via the same mechanisms

- Awareness of gender inequities is required, for women high cognitive social capital and for men high collective efficacy, to have a salutary role for mental health

- Our model implies that individuals may suffer from posttraumatic stress through the impact of the disaster on their community, even if not individually impacted

\section{INTRODUCTION}

Increasingly, scholars and practitioners in the domain of humanitarian emergency settings, such as after natural disasters, have called for interventions that incorporate the socioecological perspective into their design (cf. De Jong, Berckmoes, Kohrt, Song, Tol \& Reis, 2015; Schölmerich \& Kawachi, 2016; Tol, Pugato, Bass, Galappatti \& Eaton, 2015). This perspective suggests that disaster mental health is not only defined by individual characteristics (e.g. individual coping style and coping history) but also by the contexts or communities in which the individual lives (e.g., social networks; Miller, Kulkarni \& Kushner, 2010; Velázquez, Rivera Holguín $\&$ Morote, 2017). This suggestion concurs with the current undisputed notion in both practice and research that disaster mental health is affected by the process of individual suffering

\begin{tabular}{|l|l|}
\hline \multicolumn{2}{|c|}{ Access this article online } \\
\hline Quick Response Code: & $\begin{array}{l}\text { Website: } \\
\text { www.interventionjournal.org }\end{array}$ \\
\cline { 2 - 2 } & \\
& \\
\hline
\end{tabular}

as well as by the erosion of social fabric in society (Wind, Fordham, \& Komproe, 2011; Wind \& Komproe, 2012).

A dominant argument for multilevel interventions is that they will have an impact on multiple aspects of health when compared to single level initiatives (Aguirre-Molina \& Gorman, 1996). These claims are, however, based on limited empirical data (Lieberman, Golden, \& Earp, 2013). Schölmerich \& Kawachi (2016) argue that instead of operating on the assumption that extending the levels of

Address for correspondence: Tim Wind, Centrum '45, Diemen, The Netherlands.

E-mail: timrwind@gmail.com

This is an open access journal, and articles are distributed under the terms of the Creative Commons Attribution-NonCommercial-ShareAlike 4.0 License, which allows others to remix, tweak, and build upon the work non-commercially, as long as appropriate credit is given and the new creations are licensed under the identical terms.

For reprints contact: reprints@medknow.com

How to cite this article: Wind, T. R., \& Komproe, I. H. (2018). Closing the gap between disaster mental health research and practice: evidence for socio-ecological mental health interventions through multilevel research. Intervention, 16(1), 5-13. 
Wind \& Komproe: Closing the gap between disaster mental health research and practice

intervention will increase its impact, a more relevant issue that should be addressed is to consider why multilevel interventions might be advantageous within the disaster context. More specifically, the socio-ecological perspective implies that there are 'links' between the individual and community level, meaning that these levels influence each other (Schölmerich \& Kawachi, 2016). However, the interaction between both levels on disaster mental health is far from clear (Berry \& Welsh, 2010; Engström, Mattsson, Järleborg, \& Hallqvist, 2008).

Hence, the first step in this process is to reveal how disaster mental health is affected simultaneously at the individual level and at community level (Almedom, 2005). Simultaneously researching two conceptual levels (individual mechanisms associated with suffering and social mechanisms within the community) requires multilevel statistical procedures (Muthén, 1994). Dunn and colleagues (2014) proposed two relevant multilevel techniques that will advance our understanding and conceptualisation of disaster mental health: multilevel structural equation modelling and multilevel confirmatory factor analysis.

In this paper, we summarise published results from a research programme in which we applied both types of multilevel analyses. First, we demonstrate how the social context is related to post disaster mental health (Wind \& Komproe, 2012). Additionally, previously unpublished results on the role of gender differences within these mechanisms, associated with mental health outcomes in a post disaster context, are discussed. Within the post disaster context, social epidemiologists discern at least three prominent constructs that have been shown to be related to mental health (Kawachi \& Subramanian, 2006; McKenzie, Whitley \& Weich, 2003): structural and cognitive components of social capital, and collective efficacy. Structural social capital refers to the presence of community linkages, while cognitive social capital refers to the appreciation of these community linkages in terms of trust, mutual help and reciprocity (Harpham, Grant \& Thomas, 2002). Collective efficacy refers to the neighbourhoods' capacity to deal adequately with environmental demands and to achieve goals through its social organisation that cannot be achieved by individuals alone (Sampson, Raudenbush \& Earls, 1997). Second, ignoring the role of context in disaster research has been shown to have severe consequences for the interpretation of mental health outcomes (Wind, Joshi, Kleber \& Komproe, 2014). Finally, implications of this study's findings for post disaster interventions and research are discussed.

\section{Methods}

\section{Sample}

To examine the complex nature of the impact of natural disasters, studies were conducted in regions in England and India that were affected by floods.

A cross sectional community survey was conducted in Morpeth, England. Morpeth is a small town located in the county of Northumberland, with approximately 15,000 inhabitants. Demographically, Morpeth comprises a relatively aged population, as many choose to retire there. On the 5th and 6th of September 2008, Morpeth was struck by intensive rainfall and the ground water rose rapidly, resulting in the river flowing through the centre bursting its banks. Consequently, Morpeth was hit by one of its worst floods since 1963. Almost a thousand properties were flooded due to rising water. This study was implemented in cooperation with Northumbria University, Newcastle, UK.

The other study was conducted in Uttar Pradesh, India. The Bahraich District, in Uttar Pradesh, is annually hit by floods such as those that occurred in July and August 2008. In the region, a disaster affected group with a non affected group were compared in October 2008. The affected region is situated between the river and a dam. The region on the other side of the dam was unaffected and identified as a non affected group. This study was conducted in collaboration with the University of Delhi, India.

\section{Statistical procedure}

The social mechanisms that determine disaster mental health: multilevel structural equation modelling

Within the English dataset, the several pathways between social capital defined at the community level (i.e. postcode level) and posttraumatic stress and the associated mechanisms defined at the individual level were examined. A two-step multilevel structural equation modelling procedure (ML-SEM) was applied.

In the first step, the most constrained model that has the relative best fit indicated by its chi-square value compared to the chi-square values of more and less constrained models (Best Fitting (BF) model, see Anderson \& Gerbing, 1988) was applied. To avoid fully data driven path models, analyses were confined to models in which only modifications of the models supported by the literature were allowed. In the second step, the within and between level variance of both the individual and community variables were modelled simultaneously through a stepwise procedure. The community level random effect of the intercept was assumed to be normally distributed with a mean of zero. (For a detailed description of this analysis and procedure see Wind \& Komproe, 2012).

Secondary analyses of the data from the community survey in Morpeth were used to show gender differences in the effects of social mechanisms on post disaster mental health. For these analyses, two datasets were constructed for women and men and used the same strategies and statistical procedures (Multilevel Structural Equation Modelling, Wind \& Komproe, 2012).

\section{A second reason to apply multilevel analyses: the impact of the disaster on stand alone mental health outcomes - a question of construct validity}

In the Indian dataset, the construct validity of the factor structure of the HSCL-25 in the Indian dataset was first established; therefore, a series of factor models for relative fit was tested: (a) a one factor model with all items loaded 
Wind \& Komproe: Closing the gap between disaster mental health research and practice

on one factor; (b) an orthogonal two factor model for the items of the subscales of anxiety and depression loaded on two independent factors; and (c) an oblique two factor model for the items of the subscales of anxiety and depression loaded on correlated factors. On the basis of the results of this first set of analyses, the best-fitting factor structure out of the three a-priori specified factor models was used in the subsequent steps. Further, a multi-sample confirmatory factor analysis (CFA) was performed to evaluate equality of factor structures by testing a series of hypotheses about the robustness of the factor structure across groups (Jöreskog \& Sörbom, 1993). Similarity of patterns of factor loadings can be defined on different levels; thus, there are different hypotheses to test the similarity of factorial composition (Jöreskog \& Sörbom, 1993). Different hypotheses of factorial invariance were tested by comparing the absolute fit of different factor models (Byrne, Shavelson, \& Muthén, 1989). In this study, the following hierarchical models were distinguished: (a) a model in which the pattern of factor structure is equal across samples (Model A); (b) Model A with the additional constraint that the factor loadings are equal across samples (Model B); (c) Model B with the additional constraint that the error variances are equal across samples (Model C); and (d) Model $\mathrm{C}$ with the covariance of the factor items equal across samples (Model D). The difference in $\mathrm{X}^{2}$ values among (a) Model A and Model B, (b) Model B and Model C, and (c) Model C and Model D was computed. Finally, a four step procedure of MCFA was applied to identify the proportion of the covariance between observed items that refers to a shared context level (Dyer, Hanges \& Hall, 2005). In the procedure, within group variance (i.e., variance relevant for the mental health constructs at the individual level) is distinguished from between group variance (i.e., nested variance across groups; Muthén, 1994). (For a detailed description of this analysis see Wind and colleagues, 2014).

\section{RESULTS \\ The social mechanisms that determine disaster mental health}

In line with the socio-ecological perspective, findings from flood survivors in Morpeth, England showed how the cross level interplay between these social community constructs and individual psychosocial variables determines the individual experience of disaster mental health problems (Wind \& Komproe, 2012; Wind et al., 2011).

On the individual level, a natural disaster evokes an individual subjective experience of the event as stressful or not (i.e., primary appraisal in the traditional models based on the stress-coping theory of Lazarus and Folkman, 1984; Wind \& Komproe, 2012; Wind Fordham \& Komproe, 2011). Subsequently, an individual is forced to cope with his or her perceived threats, emotions and the disaster related demands. The assumption is that individuals need to address (i.e. cope with) external demands and that increased coping behaviour reflects a certain degree of mastery over the situation. Our findings showed that in the face of overwhelming disaster related demands, the individual is forced by these perceived demands to employ several coping strategies simultaneously (such as turning to religion, dealing with emotions and approaching situations actively). This process reflects a search for the best coping strategy among apparently less efficient and less effective ways of individual coping with the disaster and its consequences (Wind \& Komproe, 2012). Findings also showed that increased individual coping efforts (i.e. applying several coping strategies simultaneously) can be interpreted as inadequate coping with the perceived threat and as a consequence the intensity of coping efforts is related to more symptoms of posttraumatic stress (Wind \& Komproe, 2012). In contrast to the malignant effect of increased coping efforts, the study found that receiving social support was directly salutary for symptoms of posttraumatic stress (Norris \& Kaniasty, 1996).

On the community level, three constructs within the social context were revealed to have a cross-level association with the earlier discussed individual process that is indirectly health sustaining, rather than a direct association of the social context with the individual disaster mental health condition (Wind \& Komproe, 2012). These 'cross level effects' (cf. Blakely \& Woodward, 2000) are depicted by the dotted lines in Figure 1. Our findings showed that the individual psychosocial resources (i.e. coping behaviour and social support) are employed more parsimoniously and efficiently when disaster affected individuals can rely on a trustworthy and effective social community that is rife with social linkages. In Wind \& Komproe (2012), we termed this positive mechanism 'the cross level conservation of individual psychosocial resources' (cf. Hobfoll, 1989). This conservation of individual psychosocial resources decreased the association between the (traumatic) appraisal of the disaster and posttraumatic stress. As a result, individuals in communities with levels of high social capital perceive that there are more resources at their disposal to deal with posttraumatic stress. This salutary phenomenon, namely that the collective can conserve individual psychosocial resources, is the major contribution of this research programme. Although the tenet that the conservation of resources is beneficial for individuals is not new (see Conservation of Resources Theory; Hobfoll, 1989; Kawachi \& Berkman, 2001; Lin, Ye, \& Ensel, 1999), the authors are the first to empirically show the cross level interplay between social community factors (e.g. social capital) and individual psychosocial resources. Such cross level understanding is indispensable to understand both the onset and longitudinal trajectories of posttraumatic stress.

These results indicate an alternative contextual explanation for individual posttraumatic mental health complaints in post disaster settings. Namely, the individual processes to deal with this stress can be moderated and mediated by (changing) communal factors, and in some cases, be used to explain posttraumatic stress without direct or indirect exposure. Our model implies that even in the absence of a personal disaster experience, individuals may suffer from posttraumatic stress through the impact of the disaster on their community (e.g. perceived destruction of available protective social mechanisms and resources. This finding concurs with research of Schlenger and colleagues (2004), 
that about $4 \%$ of Americans living far from the traumatic events developed probable posttraumatic stress disorder (PTSD), by watching television coverage of the attacks in the comfort of their living rooms. In the same spirit, McNally (2009) pointed out that this expansion of the concept of trauma renders it less plausibly to assign causal significance to the stressor itself, and underscores the need to look at vulnerability factors such as the loss of social fabric within communities.

\section{Gender differences in social mechanisms}

Within the cross level mechanism that associates dimensions of social capital with the individual mental health process, men and women showed specific gender tendencies: communal coping mechanisms among women reflect a tendency of emotion focused coping, whereas men show a tendency of problem focused coping (cf. Punamäki, Salo, Komproe, Qouta, El-Masri \& De Jong, 2008).

Findings showed that, especially among women, high levels of cognitive social capital were associated to more effective and less coping efforts (see Figure 2). This finding suggests that within communities that provide the opportunity to share the disaster experience with - and experience empathy from - community members (i.e. high cognitive social capital), especially women were inclined to use their resources more effectively to cope with the situation (Hobfoll, 1989). This efficient and parsimonious use of individual coping efforts among women was ultimately associated with less posttraumatic stress.
For men, high collective efficacy was generally associated with mobilising less social support (see Figure 3). This efficient and parsimonious use of individual social support among men was ultimately associated with less posttraumatic stress. The finding that collective efficacy of communities was particularly relevant for men indicates that especially men were aware that they 'sink or swim together with their neighbours' when dealing with disaster related demands. That is, particularly men relied on successful partners with whom to collaborate, join and solve the often large scale disaster related problems that are beyond the reach of any individual (Eriksson, 2011; Kawachi \& Berkman, 2001; Sapag \& Kawachi, 2007; Solomon, 2003). In this respect, Benight (2004) claimed that the more affected individuals are empowered through collaboration with their neighbours, the more quickly these individuals will surpass mental health problems.

\section{Why it is vital to apply multilevel analyses: the impact of the disaster on stand alone mental health outcomes}

With the analyses of the data from flood survivors in the Bahraich District, in Uttar Pradesh, India, it was shown that multilevel research on disaster mental health is not a matter of choice, but a necessity (Wind et al., 2014). Single level research (either on the individual or community level) is associated with severe conceptual problems that have likely plagued post disaster mental health thus far. These problems stem from the multilevel nature of disaster

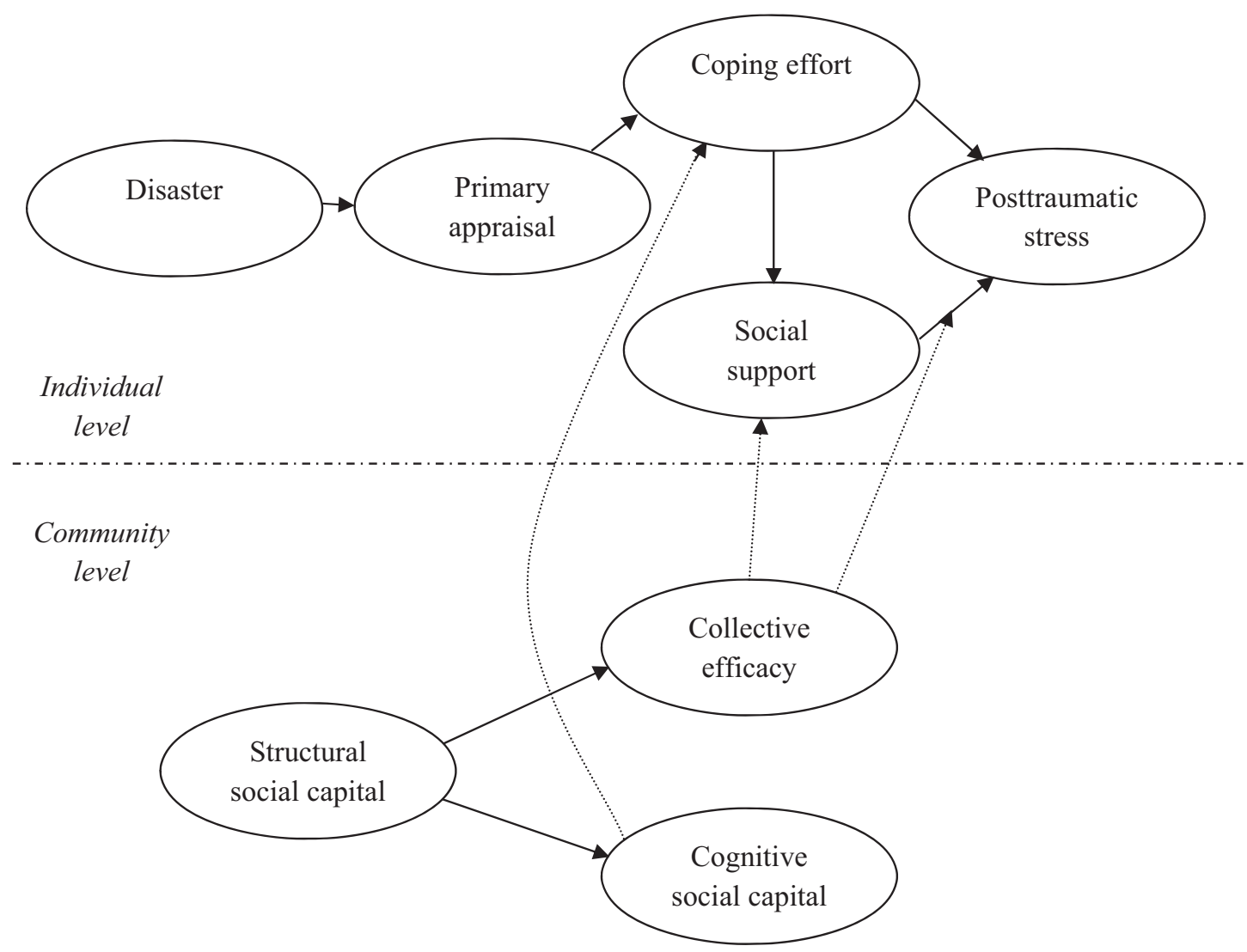

(Wind \& Komproe, 2012)

Figure 1: The conceptual multilevel model (Wind \& Komproe, 2012). 
Wind \& Komproe: Closing the gap between disaster mental health research and practice

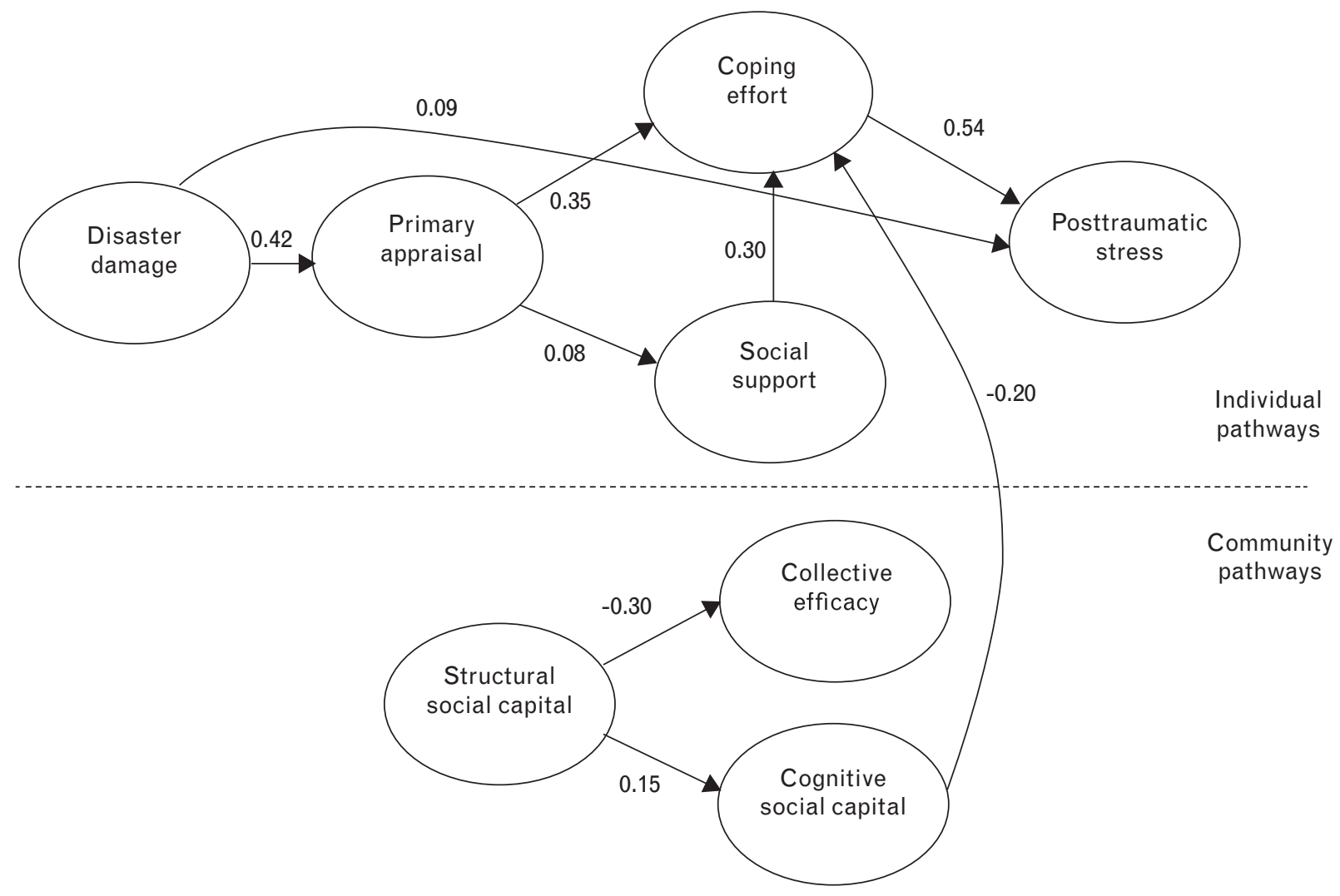

Figure 2: The multilevel model for women.

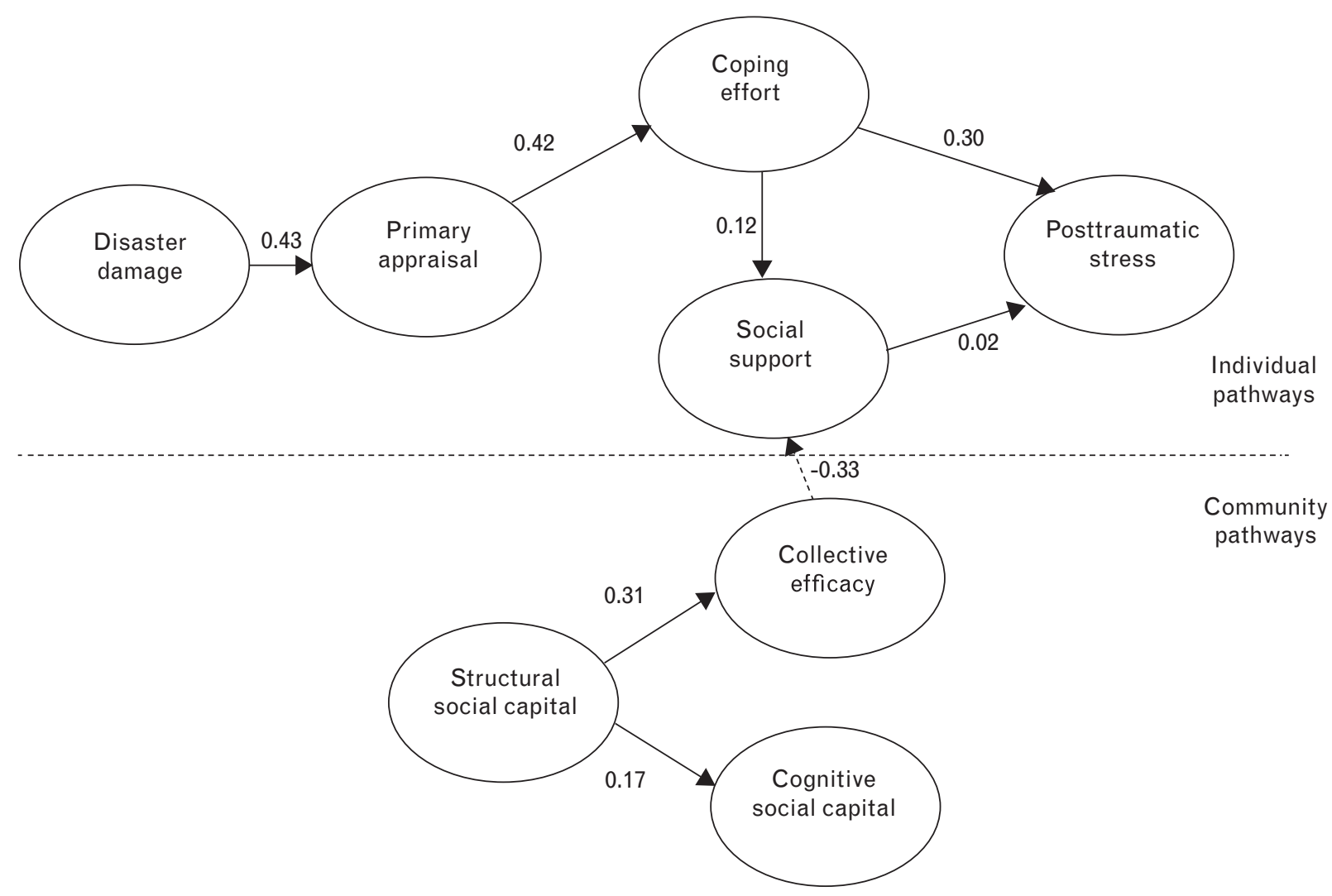

Figure 3: The multilevel model for men. 
Wind \& Komproe: Closing the gap between disaster mental health research and practice

mental health, and cannot be demonstrated without the use of multilevel analyses.

Equivalent to the two level post disaster mental health model (that specifies variables both on the individual and community level), it was demonstrated that there are actually two mechanisms that affect (statistical) variation in mental health outcomes across disaster groups (and disaster studies; Wind et al., 2014). Most disaster mental health research relied on screening outcomes due to the practical applicability of screening instruments. However, this study showed that the score on the items of the screener can be explained by the presence of the underlying (latent) mental health construct (objective of the screening) and by the shared or nested variance of the items that refers to the shared context that influences individual observed scores (see e.g. neighbourhood studies; Wind \& Komproe, 2012). The consequence of this phenomenon is that the covariance between observed mental health symptoms will refer (i) to the latent mental health concept of interest and (ii) the shared experience of living in the same eroded context (e.g. Dyer et al., 2005). When the latter source of covariance (so called 'nested variance') is ignored, the measurement of the underlying mental health concept is biased (e.g. measurement error; Muthén, 1994; Kreft \& De Leeuw, 1998). It has been suggested that this phenomenon may contribute to unwanted variation of outcomes across disaster studies. In Wind et al. (2014) we showed excessive nested variance in a disaster affected population. This problem of excessive 'nested variance' is likely to contribute substantially to variation across disaster studies, but notably not to mental health variation that Rodin \& van Ommeren (2009) refer to. The problem of nested variance is also associated with another important methodological problem. After (statistically) dissecting the nested variance problem, most of the time the construct validity of the assessment was revealed to be poor and unstable across both groups. This means that the scores on screening instruments might refer to different concepts across study samples and populations. The methodological problem of unequal construct variance ultimately refers to the following issue: whether specific mental health symptoms may constitute actual mental health problems depends on the context in which they occur. For instance, anxiety (e.g. being on high alert to danger, tension and fear) may be an adequate reaction in an environment that has recently been hit by a flood and may be struck again. Yet, these same symptoms may be an inadequate reaction in an unaffected context, and may in such a context represent the actual 'stand alone' individual mental health problems that screening instruments intend to measure. Accordingly, we found that mental health problems held different meaning across both groups. The problem of comparing unequal constructs cannot be dismissed without the required analyses (M1-CFA). Yet, the demonstrated multilevel analyses in this paper have, however, not been applied in disaster mental health research and, therefore, the size of the problem is hard to estimate.

\section{Discussion}

Scholars and practitioners in the domain of humanitarian emergency settings, such as after natural disasters, have called for interventions that incorporate the socio-ecological perspective into their design (De Jong et al., 2015; Schölmerich \& Kawachi, 2016; Tol et al., 2015), because a dominant (as yet untested) argument for multilevel interventions is that they will have a larger impact on health outcomes when compared to single level initiatives (Aguirre-Molina \& Gorman, 1996). The socio-ecological perspective implies that there are 'links' between the individual and community level, meaning that these levels influence each other (Schölmerich \& Kawachi, 2016).

Within our body of research, we substantiated evidence for the assumption underlying socio-ecological multilevel interventions: we were able to reveal the links between the individual process that determines disaster mental health and the social community one lives in by employing multilevel analyses (Kawachi, 2004). Despite its usefulness and necessity, multilevel techniques have hardly been applied in disaster mental health research. This hesitant attitude of disaster researchers stems from statistical difficulties to conduct multilevel analyses (Miller et al., 2007). Yet, recent advances in statistical packages (such as MPlus, Muthén, 1994) render multilevel analyses more easily applicable.

In this research programme, we demonstrated two types of multilevel analyses that are of particular interest (see also Dunn et al., 2014). First and foremost, multilevel structural equation modelling can be helpful in the identification of variables that either moderate or mediate the impact of disasters on mental health, in effect laying out conceptual roadmaps for empirically based interventions (Rasco \& Miller, 2004 in Miller et al., 2007). Through this type of analysis, not only how disaster affected social mechanisms are related to disaster mental health are revealed, but that these mechanisms also explain ambiguous outcomes in the relationship between social capital and mental health thus far. More specifically, distinct functions of individual variables or resources and community resources in our cross level models were also revealed. First, individual factors are directly related to disaster mental health. This means that individual factors are directly stress related (high coping effort) and may be directly stress mitigating (high social support). Second, the social context is indirectly related to disaster mental health, revealing a cross-level association of the social context with individual factors (coping effort and social support), rather than a direct relationship with disaster mental health. This cross-level association demonstrates that the social context is indirectly health sustaining. By using multilevel structural equation modelling, we revealed a much closer reflection of reality than the most commonly applied bivariate approach in disaster mental health research that attempts to link social capital directly to mental health.

Finally, the procedure of multilevel confirmatory factor analysis used in Wind et al. (2014) allows dissection of the variance at the individual level that refers to disaster mental health constructs from contextual level variance that refers 
Wind \& Komproe: Closing the gap between disaster mental health research and practice

to both the disaster affected and non disaster affected group, and to examine the validity of the individual level factor structure across both groups. The application of these two types of multilevel analyses (Dyer et al., 2005; Muthén, 1994) will advance our understanding of mental health in disaster contexts (Kawachi \& Subramanian, 2006).

\section{Interventions on the social context: single level or multilevel}

This multilevel conceptualisation shifts the perspective of disaster mental health from the pure biomedical 'disease' approach to mental health as a pathological process to a biopsychosocial definition of mental health in terms of 'illness'. Illness is more broadly defined as a feeling, an experience of lack of health which is personal and entwined in the social context (Boyd, 2000). Congruently, the process that determines post disaster mental health is multifactorial and embedded in the interaction between the individual process and the social context.

Our results point out that community interventions directed at the social context are not just compensatory to individual oriented interventions, but rather fundamental to address post disaster mental health. The multilevel conceptualisation of disaster mental health indicates a need to intervene simultaneously within the social community level and on the individual level (Schölmerich \& Kawachi, 2016). Both intervention levels are inextricably linked to one another, and whether individual suffering (e.g. posttraumatic stress) is indeed curbed, depends on the implementation of intervention at both levels. When (perceived) social capital is restored, there is often improvement in the individual member's functioning (Jordans et al., 2013). Without facilitating adequate functioning of individuals in the community, individual mental health problems are not likely to abate. At the same time, for a small group of affected individuals with sustained and severe mental health problems, community based interventions may not be enough. And within these community based interventions that restores social capital, these individuals may be referred to mental health professionals for individual treatment. Notably, these community based interventions may not only provide a link to individual interventions, but social linkages within the community (i.e. stocks of social capital) also provide a platform to tie post disaster relief initiatives by other disciplines to individual suffering (e.g. posttraumatic stress).

The findings also imply that within these community interventions, practitioners should be mindful of, and stimulate, natural gender specific tendencies. It may be particularly salutary to actively involve men in community interventions that collectively address disaster related demands and fight future threats to floods on behalf of the community (Brune \& Bossert, 2009). To promote disaster mental health of women, in turn, it may be especially fruitful to involve women in building higher levels of trust within the community.
Pennebaker (2001, p. 517-539) recommends the facilitation of 'social sharing', for example by organising community meetings, in which women find the time to talk about the disaster and process the experience (Brune \& Bossert, 2009). As such, these community interventions will put a halt to individual psychosocial resource losses for both men and women, and protect affected individuals against disaster mental health problems.

Interestingly, our findings indicate that community interventions that promote the social context and individual oriented interventions are not only geared towards the same end of improving individual mental health (Kawachi \& Subramanian, 2006), but also exert their effect on mental health via the same individual mechanisms. Namely, cognitive behavioural interventions - the individual intervention of choice to address prolonged disaster related distress (Van Ommeren, Morris \& Saxena, 2008) - alter the relationship between the original emotional response (cf. primary appraisal) and current distress, and mild individual behaviour towards a more adequate response (coping and seeking social support). We showed that cultivation of social capital exerts its salutary influence on disaster related distress via the exact same mechanisms. Thus, on the basis of our empirical results, one may conclude that the cultivation of community social capital may help to decrease the need for individual psychological interventions (Hobfoll et al., 2007; Van Ommeren \& Wessels, 2007).

\section{Conclusions}

In this paper, evidence from a research programme for the underlying assumption of socio-ecological multilevel interventions that are preached in practice (see e.g. Abou-Saleh \& Hughes, 2015) were summarised. That is, the links between individual characteristics that determine disaster mental health and the social environment one lives in were shown. Also, the consequences of ignoring the effect of shared context on the assessment of mental health outcomes were shown. The authors invite scholars to similarly apply multilevel techniques (SEM and CFA) to advance understanding of disaster mental health research (see also Dunn et al., 2014), to close the gap between traditionally epidemiological oriented disaster mental health research and common practice in post disaster settings. Longitudinal research will further help us to understand the development of disaster mental health problems, and develop adequate mitigation strategies to confront the increasing numbers of disaster affected individuals with mental health problems. Moreover, an important step is to provide evidence that specific dimensions of social capital can intentionally be promoted with beneficial effects on disaster mental health outcomes. Unfortunately, despite decades of disaster interventions that promote social capital, this type of research in post conflict or post disaster is still very rare (Brune \& Bossert, 2009; Verduin, Smid, Wind \& Scholte, 2014). 
Wind \& Komproe: Closing the gap between disaster mental health research and practice

\section{References}

Abou-Saleh, M. T., \& Hughes, P. (2015). Mental health of Syrian refugees: looking backwards and forwards. Lancet Psychiatry, 2 (10), 870-871.

Aguirre-Molina, M., \& Gorman, D. M. (1996). Community-based approaches for the prevention of alcohol, tobacco, and other drug use. Annual Review of Public Health, 17, 337-358.

Almedom, A. M. (2005). Social capital and mental health: An interdisciplinary review of primary evidence. Social Science \& Medicine, 61 (5), 943-964.

Anderson, J. C., \& Gerbing, D. W. (1988). Structural equation modeling in practice: A review and recommended two-step approach. Psychological Bulletin, 103(3), 411-423.

Benight, C. C. (2004). Collective efficacy following a series of natural disasters. Anxiety, Stress, and Coping, 17(4), 401-420.

Berry, H. L., \& Welsh, J. A. (2010). Social capital and health in Australia: An overview from the household, income and labour dynamics in Australia survey. Social Science \& Medicine, 70(4), 588-596.

Blakely, T. A., \& Woodward, A. J. (2000). Ecological effects in multilevel studies. Journal of Epidemiology and Community Health, 54, 367-374.

Bollen, K. A. (1991). Structural equations with latent variables. New York, NY: Wiley Interscience Publications.

Boyd, K. M. (2000). Disease, illness, sickness, health, healing and wholeness: exploring some elusive concepts. Medical Humanities, 26(1), 9-17.

Brune, N. E., \& Bossert, T. (2009). Building social capital in post-conflict communities: Evidence from Nicaragua. Social Science \& Medicine, 68(5), 885-893.

Byrne, B. M., Shavelson, R. J., \& Muthén, B. (1989). Testing for the equivalence of factor covariance and mean structures: The issue of partial measurement invariance. Psychological Bulletin, 105, 456-466.

De Jong, J. T., Berckmoes, L. H., Kohrt, B. A., Song, S. J., Tol, W. A., \& Reis, R. (2015). A public health approach to address the mental health burden of youth in situations of political violence and humanitarian emergencies. Current Psychiatry Reports, 17(7), 60.

Dunn, E. C., Masyn, K. E., Yudron, M., Jones, S. M., \& Subramanian, S. V. (2014). Translating multilevel theory into multilevel research: Challenges and opportunities for understanding the social determinants of psychiatric disorders. Social Psychiatry and Psychiatric Epidemiology, 49(6), 859-872.

Dyer, N. G., Hanges, P. J., \& Hall, R. J. (2005). Applying multilevel confirmatory factor analysis techniques to the study of leadership. The Leadership Quarterly, 16, 149-167.

Engström, K., Mattsson, F., Järleborg, A., \& Hallqvist, J. (2008). Contextual social capital as a risk factor for poor self-rated health: a multilevel analysis. Social Science \& Medicine, 66, 2268-2280.

Eriksson, M. (2011). Social capital and health - implications for health promotion. Global Health Action, (4). Available at: http://www. globalhealthaction.net/index.php/gha/article/view/5611.

Harpham, T., Grant, E., \& Thomas, E. (2002). Measuring social capital within health surveys: Key issues. Health Policy and Planning, 17(1), 106-111.

Hobfoll, S. E. (1989). Conservation of resources: a new attempt at conceptualizing stress. American Psychologist, 44(3), 513-524.

Hobfoll, S. E., Watson, P., Bell, C. C., Bryant, R. A., Brymer, M. J., Friedman, M. J., \& Ursano, R. J. (2007). Five essential elements of immediate and mid-term mass trauma intervention: Empirical evidence. Psychiatry, 70(4), 283-315.

Jordans, M. J., Tol, W. A., Susanty, D., Ntamatumba, P., Luitel, N. P., Komproe, I. H., \& de Jong, J. T. (2013). Implementation of a mental health care package for children in areas of armed conflict: A case study from Burundi, Indonesia, Nepal, Sri Lanka and Sudan. PloS Medicine, 10(1), e1001371.

Jöreskog, K., \& Sörbom, D. (1993). Lisrel 8: Structural equation modelling with the SIMPLIS command language. Chicago, IL: Scientific Software International.

Kawachi, I. (2004). Commentary: Reconciling the three accounts of social capital. International Journal of Epidemiology, 33(4), 682-690.
Kawachi, I., \& Berkman, L. F. (2001). Social ties and mental health. Journal of Urban Health, 78(3), 458-467.

Kawachi, I., \& Subramanian, S. V. (2006). Measuring and modeling the social and geographic context of trauma: Amultilevel modeling approach. Journal of Traumatic Stress, 19(2), 195-203.

Kreft, I., \& De Leeuw, J. (1998). Introducing multilevel modeling. Thousand Oaks, CA: Sage.

Lazarus, R. S., \& Folkman, S. (1984). Stress, Appraisal, and Coping. New York, NY: Springer.

Lieberman, L., Golden, S. D., \& Earp, J. A. (2013). Structural approaches to health promotion: What do we need to know about policy and environmental change? Health Education \& Behavior, 40, 520-525.

Lin, N., Ye, X., \& Ensel, W. M. (1999). Social support and depressed mood: a structural analysis. Journal of Health and Social Behavior, 40, 344-359.

McKenzie, K., Whitley, R., \& Weich, S. (2002). Social capital and mental health. BritishJournal of Psychiatry, 181, 280-283.

McNally, R. J. (2009). Can we fix PTSD in DSMV? Depression and Anxiety, 26, 597-600.

Miller, K. E., Kulkarni, M., \& Kushner, H. (2007). Beyond traumafocused psychiatric epidemiology: Bridging research and practice with war affected populations. Am J Orthopsychiatry, 76(4), 409-422.

Muthén, B. O. (1994). Multilevel covariance structure analysis. Sociological Methods and Research, 22, 376-398.

Norris, F. H., \& Kaniasty, K. (1996). Received and perceived social support in times of stress: A test of the social support deterioration deterrence model. Journal of Personality and Social Psychology, 71 (3), 498-511.

Pennebaker, J. W. (2001). Disclosing and Sharing Emotion: Psychological, Social and Health Consequences. In: M. S. Stroebe, W. Stroebe, R. O. Hansson, \& H. Schut (Eds.), Handbook of bereavement research: Consequences, coping, and care 517-539. Washington, DC: American Psychological Association.

Punamäki, R.-L., Salo, J., Komproe, I. H., Qouta, S., El-Masri, M., \& De, Jong. (2008). Dispositional and situational coping and mental health among Palestinian political ex-prisoners. Anxiety, Stress \& Coping, 21(4), 337-358.

Rasco, L. M., \& Miller, K. E. (2004). Innovations, challenges, and critical issues in the development of ecological mental health interventions with refugees. In: K. E. Miller, \& L. M. Rasco (Eds.), The mental health of refugees: Ecological approaches to healing and adaptation 375-416. Mahwah, NJ: Erlbaum.

Rodin, D., \& van Ommeren, M. (2009). Commentary: Explaining enormous variations in rates of disorder in trauma-focused psychiatric epidemiology after major emergencies. International Journal of Epidemiology, 38(4), 1045-1048.

Sampson, R. J., Raudenbush, S. W., \& Earls, F. (1997). Neighborhoods andviolent crime: A multilevel study of collective efficacy. Science, 277(5328), 918-924.

Sapag, J. C., \& Kawachi, I. (2007). Social capital and health promotion in Latin America. Revista Saude Publica, 41(1), 139-149.

Schlenger, W. E., Caddell, J. M., Ebert, L., Jordan, B. K., Rourke, K. M., Wilson, D., \& Kulka, R. A. (2004). Psychological reactions to terrorist attacks: findings from the National Study of Americans' Reactions to September 11. JAMA, 288, 581-588.

Schölmerich, V. L., \& Kawachi, I. (2016). Translating the socioecological perspective into multilevel interventions: Gaps between theory and practice. Health Education \& Behavior, 43(1), 17-20.

Solomon, Z. (2003). Coping with war-induced stress: The Gulf War and the Israeli response. NewYork NY: Plenum.

Tol, W. A., Pugato, M., Bass, J. K., Galappatti, A., \& Eaton, W. (2015) Mental health and psychosocial support in humanitarian settings: A public mental health perspective. Epidemiology and Psychiatric Sciences, 24(6), 484-494.

Van Ommeren, M., Morris, J., \& Saxena, S. (2008). Social and clinical interventions after conflict and other large disaster. American Journal of Preventive Medicine, 35(3), 284-286.

Van Ommeren, M., \& Wessels, M. (2007). Interagency agreement on mental health and psychosocial support in emergency settings. Bulletin of the World Health Organization, 85(11), 822.

Velázquez, T., Rivera Holguin, M., \& Morote, R. (2017). Disaster and post disasters: Lessons and challenges for Community Psychology. 
Wind \& Komproe: Closing the gap between disaster mental health research and practice

In: APA Handbook of Community Psychology American Psychological Association 425-439. Washington, DC: APA.

Verduin, F., Smid, G. E., Wind, T. R., \& Scholte, W. F. (2014). In search of links between social capital, mental health and sociotherapy: A longitudinal study inRwanda. Social Science \& Medicine, 121, 1-9.

Wind, T. R., \& Komproe, I. H. (2012). The mechanisms that associate community social capital with post-disaster mental health: a multilevel mode. Social Science \& Medicine, 75(9), 1715-1720.
Wind, T. R., Fordham, M., \& Komproe, I. H. (2011). Social capital and post-disaster mental health. Global Health Action, 4, 6351.

Wind, T. R., Joshi, P. C., Kleber, R. J., \& Komproe, I. H. (2013). The impact of recurrent disasters on mental health: A study on seasonal floods in northern India. Prehospital and Disaster Medicine, 28(3), 279-285.

Wind, T. R., Joshi, P. C., Kleber, R. J., \& Komproe, I. H. (2014). The e! ect of the postdisaster contextonthe assessment of individualmental health scores. American Journal of Orthopsychiatry, 84(2), 134-141. 